\section{How should we best determine the need for inflight oxygen in patients with pulmonary arterial hypertension?}

The British Thoracic Society has recently updated the air travel recommendations suggesting that patients with precapillary pulmonary hypertension (PCPH) in functional classes (FCs) 3 and 4 should have inflight oxygen. ${ }^{1}$ This replaces the 2004 recommendations which relied upon baseline oxygen saturation $\left(\mathrm{SpO}_{2}\right)$ to determine the need for oxygen or to undergo a hypoxic challenge test (HCT). We compared the relative impact of the 2004 and 2011 guidelines on the proportion of PCPH patients who would be recommended inflight oxygen.

We have recently published the effect a HCT would have on arterial oxygen levels in 36 patients with $\mathrm{PCPH}$ and baseline Sp02>90\%. ${ }^{2}$ In this study arterial partial pressure of oxygen in $\mathrm{PCPH}$ patients fell by $2.36 \mathrm{kPa}$, (95\% CI 2.06 to $2.66 \mathrm{kPa})$ which is similar to that reported in patients with other chronic respiratory diseases. $^{3}{ }^{4}$ Twenty-five per cent of this cohort failed the HCT and would according to the 2004 guidance have been recommended inflight oxygen. This is much lower than the $53 \%$ who would require inflight oxygen if we applied the FC criteria in the 2011 recommendations. In our cohort FC was not associated with failure of the HCT.

We then extrapolated these data to predict the impact of the new recommendations on the entire population of 221 $\mathrm{PCPH}$ patients attending the Scottish Pulmonary Vascular Unit. We estimate that the 2011 recommendations increase the proportion of patients who would be advised to fly with supplementary oxygen from $47 \%$ to $68 \%$ (based on the cohort derived HCT failure rate of $25 \%)$.

The theoretical concern with $\mathrm{PCPH}$ patients on airline flights is of worsening hypoxic pulmonary vasoconstriction, elevation of mean pulmonary artery pressures and acute failure of the right ventricle. The HCT has been set aside in the 2011 recommendations because acute alveolar hypoxia may not predict this chain of events but neither is there evidence that we can achieve this with FC. Indeed studies supporting this mechanism of respiratory distress in $\mathrm{PCPH}$ patients during airline flight have yet to be performed. By contrast it has already been shown that during exercise and also sleep (both daily events) the mean pulmonary artery pressures can rise dramatically in $\mathrm{PCPH}$ patients and yet they do not suffer catastrophic right ventricle failure. ${ }^{5}$

In conclusion further studies need to be undertaken to assess the effect of hypobaric hypoxia on right ventricular function in these patients which will be important to identify accurately those who need inflight oxygen and avoid the unnecessary inconvenience and expense for those who do not.

\section{Roslyn M Burns, Martin K Johnson, Alistair Colin Church}

Respiratory Department, Scottish Pulmonary Vascular Unit, Golden Jubilee Hospital, Glasgow, UK

Correspondence to Dr Alistair Colin Church, Respiratory Department, Scottish Pulmonary Vascular Unit, Golden Jubilee Hospital, Agamemnon Street, Glasgow G81 4DY, UK; colinchurch@doctors.org.uk

Contributors All authors contributed to the design of the project. RMB and ACC recruited the patients.

Funding University of Glasgow.

Competing interests None.

Ethics approval West of Scotland ethics committee.

Provenance and peer review Not commissioned; internally peer reviewed.

To cite Burns RM, Johnson MK, Church A C. Thorax 2013:68:680

Received 28 January 2013

Accepted 29 January 2013

Published Online First 15 February 2013

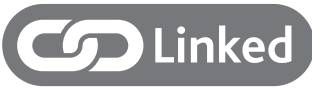

- http://dx.doi.org/10.1136/thoraxjnl-2013-203379

Thorax 2013:68:680.

doi:10.1136/thoraxjnl-2013-203344

\section{REFERENCES}

1 Shrikrishna D, Coker RK. Managing passengers with stable respiratory disease planning air travel: British Thoracic Society recommendations. Thorax 2011;66:831-3.

2 Burns RM, Peacock AJ, Johnson MK, et al. Hypoxaemia in patients with pulmonary arterial hypertension during simulated air travel. Respir Med 2013:107:298-304

3 Mestry N, Thirumaran M, Tuggey JM, et al. Hypoxic challenge flight assessments in patients with severe chest wall deformity or neuromuscular disease at risk for nocturnal hypoventilation. Thorax 2009:64:532-4.

4 Dillard TA, Berg BW, Rajagopal KR, et al. Hypoxemia during air travel in patients with chronic obstructive pulmonary disease. Ann Intern Med 1989;111:362-7.

5 Raeside DA, Brown A, Patel KR, et al. Ambulatory pulmonary artery pressure monitoring during sleep and exercise in normal individuals and patients with COPD. Thorax 2002:57:1050-3. 